\title{
Gwalia mine - backfill system operational review
}

\author{
S Wilson Paterson \& Cooke (UK) Ltd, UK \\ J Snyman Paterson \& Cooke Consulting Engineers (Pty) Ltd, South Africa \\ M McGuinness Paterson \& Cooke Canada Inc., Canada \\ J Albrecht St Barbara Ltd, Australia \\ J De Vries St Barbara Ltd, Australia
}

\begin{abstract}
The Gwalia gold mine located in Western Australia has been operating its current backfill system since 2009. The backfill system prepares a paste fill from harvested mine tailings, blending these with water and binder before discharging into a gravity driven reticulation system. Currently the backfill plant operates at approximately $185 \mathrm{tph}$, delivering $130 \mathrm{~m}^{3} / \mathrm{h}$ of paste fill to a depth of approximately 1,500 m below surface.

In line with good operational practice, and as a reaction to a series of borehole blockages, Gwalia has undertaken an operational review of its backfill system. The system review considered all aspects of the operation from tailings harvesting through to plant operation procedures, maintenance planning and paste distribution, as well as establishing the root cause of the borehole failures. The overall backfill management system was also reviewed, and recommendations made.

In addition, a life of mine review has considered the requirements and implications of extending the reticulation system to $1,800 \mathrm{~m}$ below surface.

This paper presents an overview of the review along with an assessment of the current and future reticulation systems, concluding from it a number of value-adding recommendations. Additionally, comment is made on best practice in paste fill system management.
\end{abstract}

\section{Introduction}

The Gwalia underground gold mine is owned and operated by St Barbara Ltd (SBM), who purchased the operation from the administrators of the Sons of Gwalia mining company in 2005. Located several kilometres south of the town of Leonora in Western Australia, the mine extracts approximately $0.8 \mathrm{Mtpa}$ of ore from underground. Key to the underground operation is the use of paste backfill, and the system has been operational since 2009, utilising remanent mill tailings from historic tailings storage facilities located on the site. SBM has invested in the technical development of paste fill at Gwalia since 2009, with an ongoing drive for progressive improvements.

Currently, the mine is operational at a depth of approximately $1,500 \mathrm{~m}$ below surface. The life of mine plan will see this development extend to a depth of nearly $1,800 \mathrm{~m}$, and with it will follow the backfill reticulation system.

\subsection{Borehole failure}

Since 2009, backfill has been conveyed underground via Borehole \#1, and in 2011 a second, backup, borehole (Borehole \#2) was installed. Both boreholes breakthrough on the 500 level, making each borehole approximately $540 \mathrm{~m}$ long. The top $165 \mathrm{~m}$ of the boreholes are cased with steel pipe while the bottom $375 \mathrm{~m}$ are unlined. In October 2013, Borehole \#1 suffered a blockage. This blockage was cleared by immediate flushing with water and air; however, upon recommencement of filling, the hole immediately blocked again. 
In light of this second blockage, Borehole \#2 was put into operation. Borehole \#1 has since been abandoned and a third borehole installed to again intersect the 500 level.

An investigation of Borehole \#1 performed at the time of the failures included a CCTV borehole inspection, and this identified significant wear on the lined section of the borehole, as shown in Figure 1.

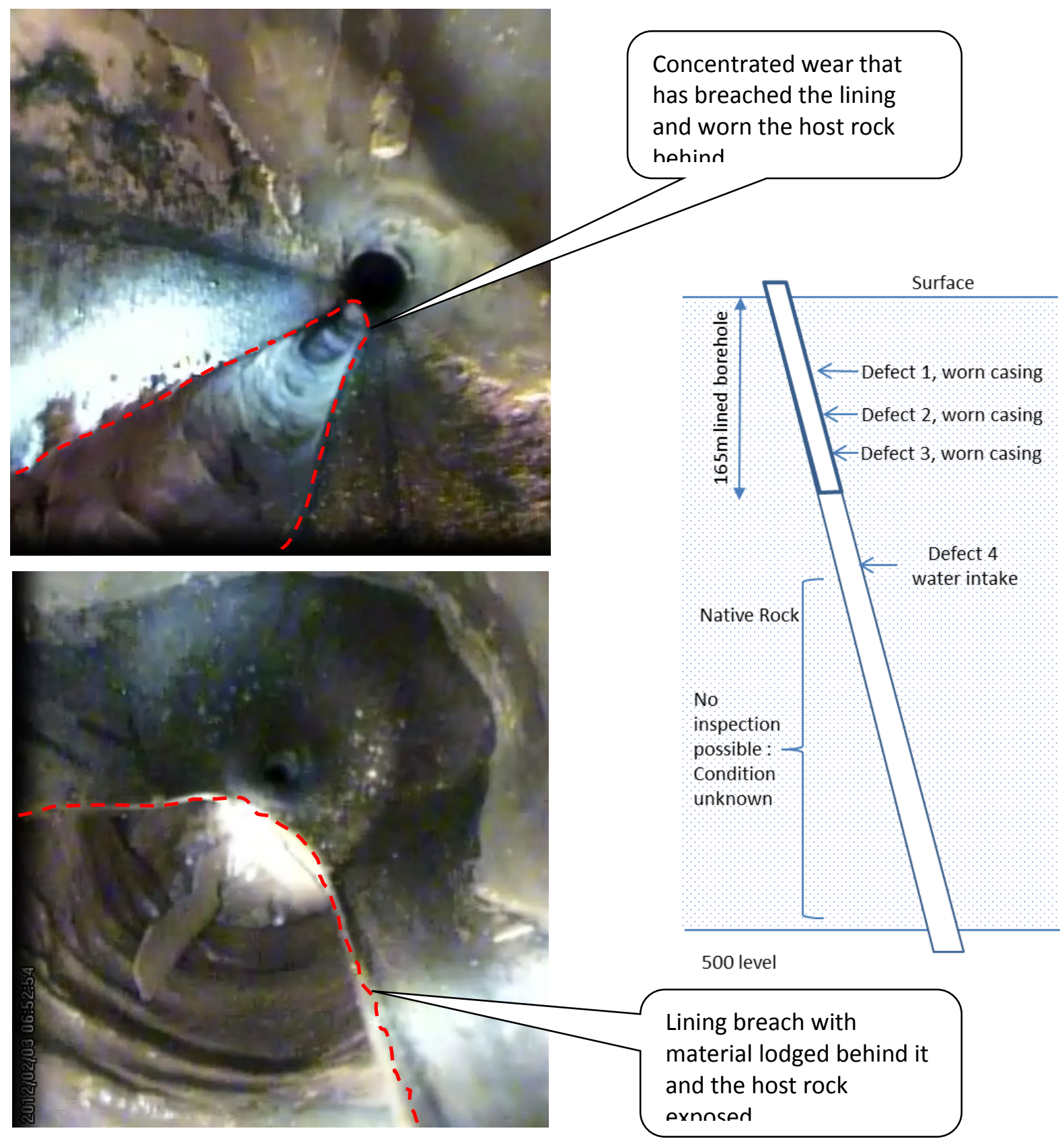

Figure 1 Camera inspection results of the surface borehole

In total, three such defects were identified within the lined section of the borehole. Additionally, a significant ground water incursion was also identified which prevented inspection of the unlined section of the hole.

The nature of the wear pattern was observed to be indicative of free falling material and therefore the subsequent investigation concentrated on the characteristics of the paste fill and the physical geometry of the reticulation system. 


\subsection{The operational review}

Prior to the borehole blockage, the operation had run well; however, SBM recognised the significance of the incident and the need to identify the root cause beyond the immediate mechanisms of the operational interruption. This initiated a review of the entire backfill system.

This review encompassed the planning, production, placement and management of backfill, examining the direct and indirect causation of the borehole blockages, as well as seeking improvements throughout the operation.

This paper presents a review of the operation and its management, as well as recent material testing undertaken by Paterson \& Cooke for SBM. This includes hydraulic analysis of the current reticulation system to determine the immediate cause of the high wear rates observed, as well as recommendations for short- and long-term remediation.

\section{Overview of the current backfill system}

\subsection{Backfill specification}

Paste backfill is used to support the high extraction ratio mining implemented at Gwalia. Further to extensive numerical modelling and backfill testing work, Gwalia has devised extensive backfill specification requirements based on the geometry and extraction sequence of stopes relative to neighbouring stopes.

The strength requirements for the stoping at Gwalia vary depending on which faces are to be exposed and the time frame for their exposure. Using a series of design charts, the engineer can identify the necessary backfill strength within the stope and reconciling this against material test data, binder addition rates are determined.

Recent material testing from 2014 has illustrated the achievable strength resulting from binder addition at various solids concentrations.

Gwalia currently uses a low heat binder conforming to the requirements of AS 3972 - special purpose cement type LH. The binder is a blend of general purpose cement and blast furnace slag. Using this binder, Gwalia typically operates with binder rates ranging from 4 to $7 \% \mathrm{~m}$.

\subsection{Backfill material properties}

The material properties of the tailings used to produce backfill are presented in Table 1.

\section{Table 1 Material properties}

\begin{tabular}{cc}
\hline Material property & Reclaimed tailings \\
\hline Solids density & $2,776 \mathrm{~kg} / \mathrm{m}^{3}$ \\
d90 particle size & $179 \mu \mathrm{m}$ \\
d50 particle size & $50 \mu \mathrm{m}$ \\
Freely settled bed packing concentration, Cbfree & $68.3 \% \mathrm{~m}$ or $43.7 \% \mathrm{v}$ \\
\hline
\end{tabular}

Recent material testing has suggested a particle-size distribution, as illustrated in Figure 2. 


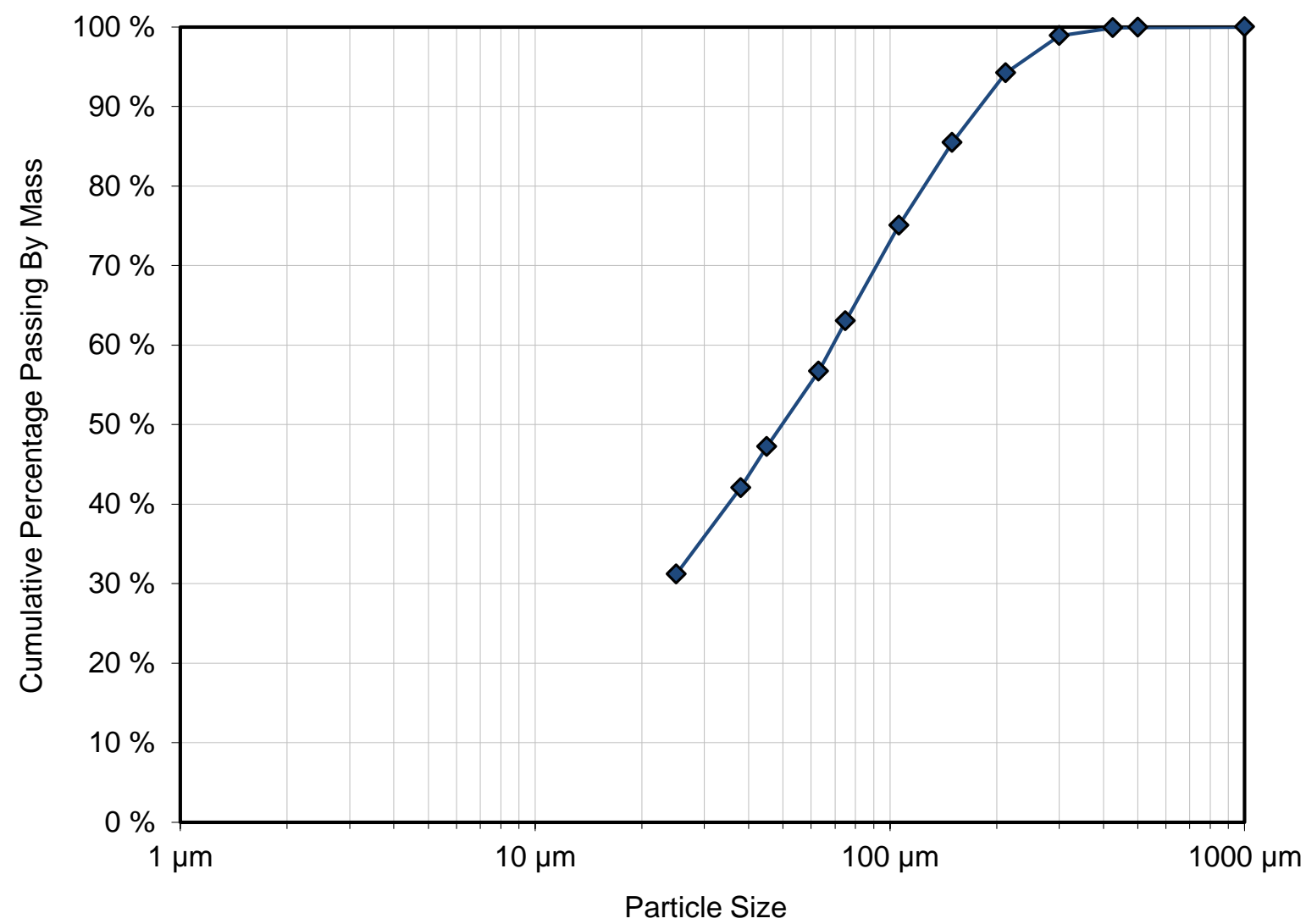

Figure 2 Particle-size distribution

\subsection{Rheological characterisation}

An Anton Paar Rheolab QC rotational viscometer with a temperature control bath was used to determine a rheogram for the uncemented and cemented backfill slurries. The rotational viscometer data was used to determine the rheological properties of the uncemented and cemented paste.

Figures 3 and 4 show the yield stress and the plastic viscosity versus mass concentration relationship, respectively. The cemented paste is more viscous than the uncemented paste. Table 2 presents the rheological correlations for the uncemented and cemented paste tested.

The rheology was used as input to the hydraulic flow model in order to determine the friction losses and the system hydraulic grade line.

Table 2 Rheological Correlations (Paterson \& Cooke 2014)

\begin{tabular}{|c|c|c|}
\hline \multirow[t]{2}{*}{ Description } & \multicolumn{2}{|c|}{ Bingham plastic model } \\
\hline & Plastic viscosity & Bingham yield stress \\
\hline \multirow{2}{*}{ Base case (uncemented) } & \multicolumn{2}{|c|}{ Applicable mass solids concentration range: $65 \% \mathrm{~m}<\mathrm{C}<77 \% \mathrm{~m}$} \\
\hline & $K_{B}=743.2 \times 10^{6} C^{70.6}$ & $\tau_{y}=37.1 \times 10^{3} C^{20.7}$ \\
\hline \multirow{2}{*}{ Base case ( $4 \%$ cemented) } & \multicolumn{2}{|c|}{ Applicable mass solids concentration range: $65 \% \mathrm{~m}<\mathrm{C}<77 \% \mathrm{~m}$} \\
\hline & $K_{B}=429.6 \times 10^{3} C^{41.5}$ & $\tau_{y}=7.6 \times 10^{3} C^{14.5}$ \\
\hline
\end{tabular}




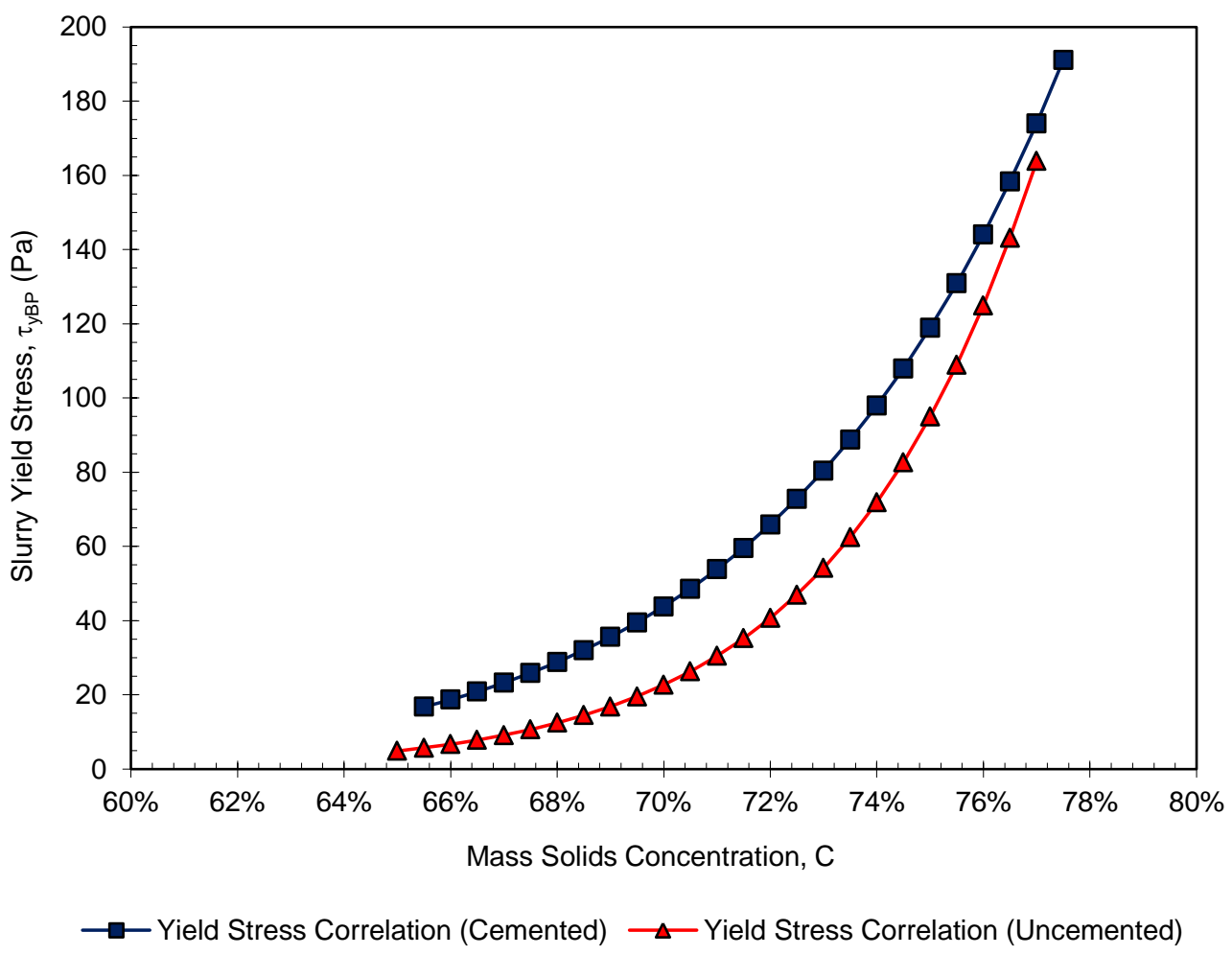

Figure 3 Yield stress versus mass solids concentration

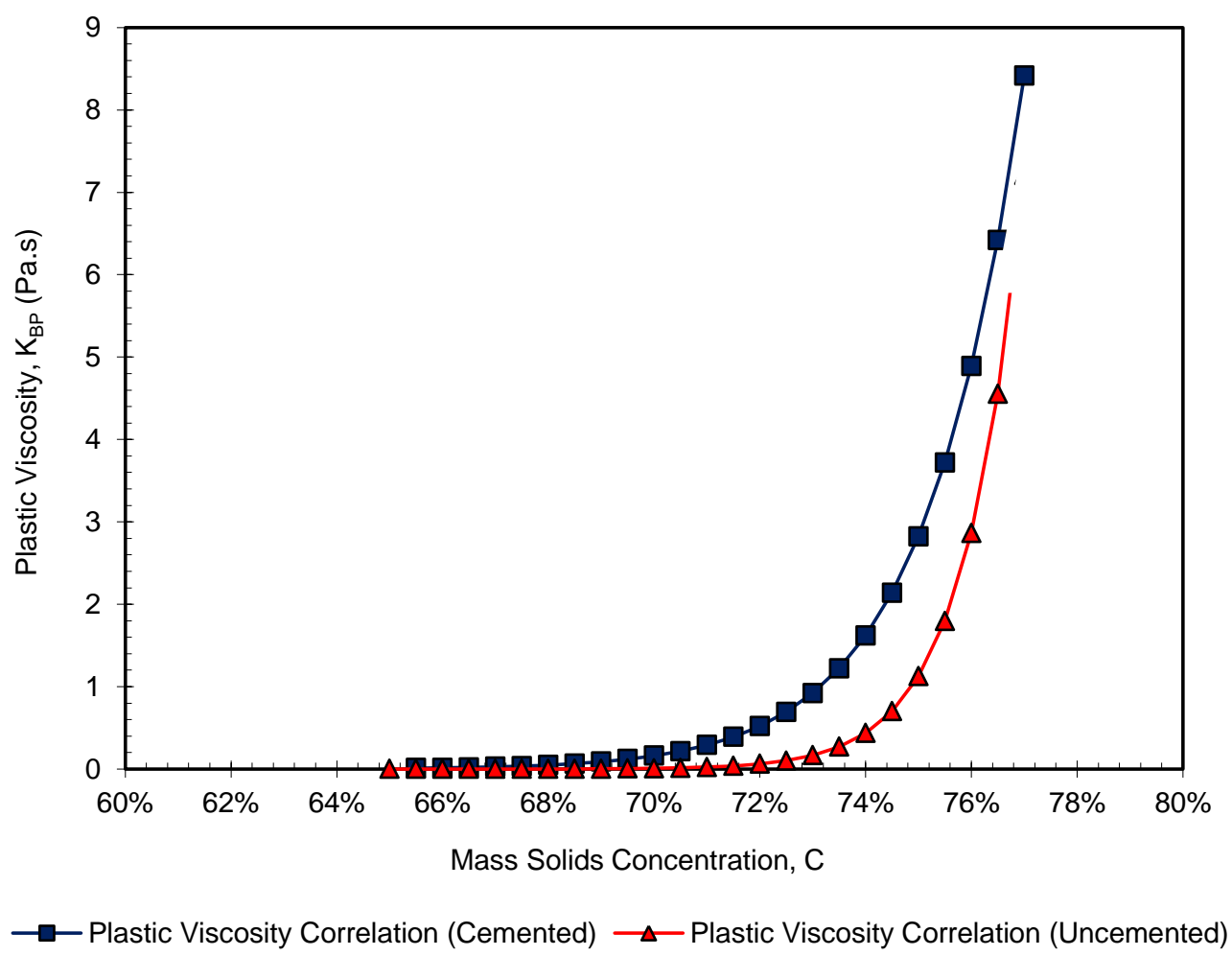

Figure 4 Plastic viscosity versus mass solids concentration 


\subsection{Backfill feed material}

Tailings has historically been harvested from one of a number of redundant old tailings facilities within the Gwalia tenement. The harvesting operation broadly includes:

- Removal of a 1 to $2 \mathrm{~m}$ waste rock capping layer.

- Excavation and screening of the tailings material to remove oversize.

- Haulage to a stockpile immediately adjacent to the paste fill plant.

The importance of thoroughly understanding the feed material and its variability cannot be overstated, especially when obtaining feed material from historical tailings deposits. It is common to encounter significant PSD variations within an old tailings deposit, reflecting changes in the previous ore processing technique, changes in ore mineralogy and/or the natural segregation that occur during hydraulic deposition. More recently, tailings material is being recovered from recently deposited tailings, allowing SBM greater understanding of the materials history.

Although SBM had conducted a large number of tests on the tailings, additional sampling and test work was recommended to better understand the variability of the tailings feed. Techniques normally used in geological modelling were also recommended to better predict the variability of material within the deposit. With this information in hand, proactive management of the feed material can be implemented to maintain a consistent PSD feed to the backfill plant, or to at least identify times when there is to be variation. This information can then be used to adjust the operation of the backfill plant to accommodate feed variability.

The review also noted that certain areas of the previous tailings deposit were wetter than others. Understanding and accounting for variations in the feed moisture is again fundamental to the success of a backfill system in delivering a consistent product.

\subsection{Backfill preparation}

The excavated material is hauled and stockpiled close to the backfill plant, from where it is rehandled by a front end loader into a feed hopper. From the hopper, a conveyor elevates the feed material up to feed a horizontal twin shaft mixer.

The mixer accommodates the feed material input, binder and additional mix water, with the latter two feed rates being controlled via a ratio against the feed material rate. This control function is based on knowledge of the moisture content in the feed, underpinning the importance of this parameter. This is especially the case with the Gwalia plant as there is no subsequent assessment of mixer power draw to define the mixed material consistency, nor is there any final rheological control loop to ensure the material meets specification.

The mixer residence time is short at approximately 30 seconds, and this limited mix time, coupled with the clay content in the feed tailings, was observed to result in inadequate mixing at the time of the review, as illustrated in Figure 5. 


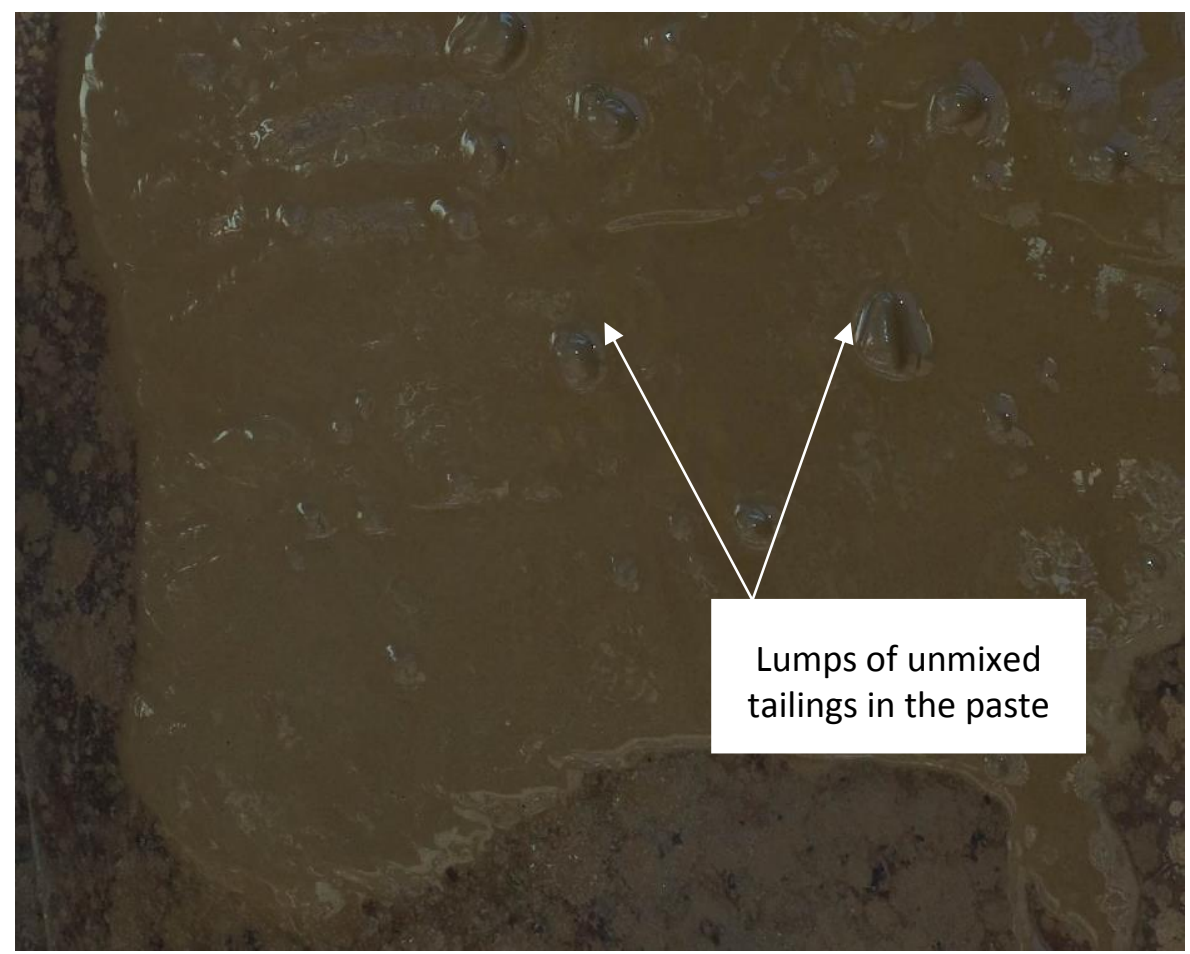

Figure 5 Inadequate mixing of paste fill, indicated by lumps of unmixed tailings in the paste

Comprehensive mixing of the feed products to yield a consistent and homogenous product is critically important to the effective operation of the reticulation system. In this scenario, the initially unmixed products will progressively mix during transit through the system which leads to a change in the paste fill consistency after it enters the reticulation system.

Mixers with larger residence times (up to three minutes), and the facility to monitor power draw and control water addition, offer improved mixing and consistency of product.

Once mixed, the Gwalia paste discharges onto a vibrating screen designed to prevent the entry of oversized material into the borehole, with undersized material passing through and into the hopper below. From the hopper the paste fill passes through to the reticulation system and into the mine.

\subsection{Reticulation system description}

The existing reticulation system extends from surface via two (one duty and one standby) $150 \mathrm{~mm}$ NB boreholes to the 500 level. From here, the system runs in a single $150 \mathrm{~mm}$ NB pipeline to the 1,260 level at which point the option exists to feed backfill through one of two different pipeline systems which extend to the 1,380 level and 1,420 level respectively. It is from each of these branches that the new system will extend to the 1,740 level, allowing for natural system redundancy as filling to all stopes on each new level can be achieved from either branch. This will ultimately allow more scope for proactive maintenance, as described further in Section 4 of this paper.

The existing and future reticulation system is graphically presented in Figure 6. For clarity, the decline has been omitted, as has the full extent of the borehole to surface. 


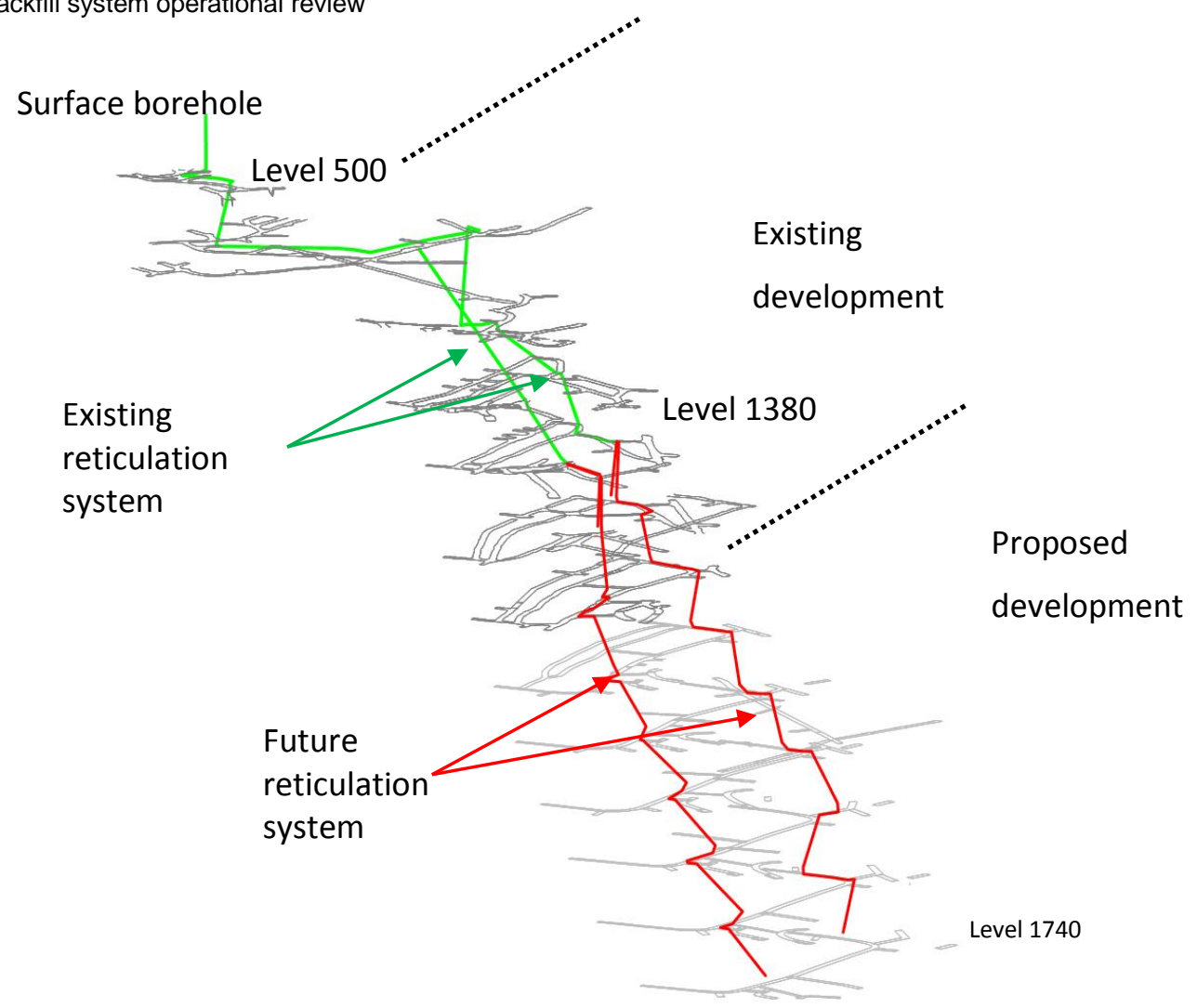

Figure 6 Current and proposed future reticulation layout

\section{Reticulation system assessment}

The reticulation system assessment sought to determine the cause for the high wear observed in Borehole \#1 based on the operation of the backfill system at the time. Further to this, recommendations have been made to improve the current system performance in the short-term and then in the long-term as part of the system expansion to the 1,740 level.

\subsection{Assessment of the current system}

The rheological correlations of the cemented sample were used to prepare a hydraulic flow model that predicts the friction losses in the system. The distribution system was originally designed as a gravity fed system relying on the elevation difference between the backfill plant and stoping area to sustain the flow. In gravity systems, a balance between the head in the system and the system friction must be established to maintain stable, full flow conditions in the pipeline.

If the available head (i.e. elevation difference between the backfill plant and stoping area) exceeds the total head loss due to friction in the reticulation system for the design flow rate, free fall will take place in the upper section of the borehole, as illustrated in Figure 7. 


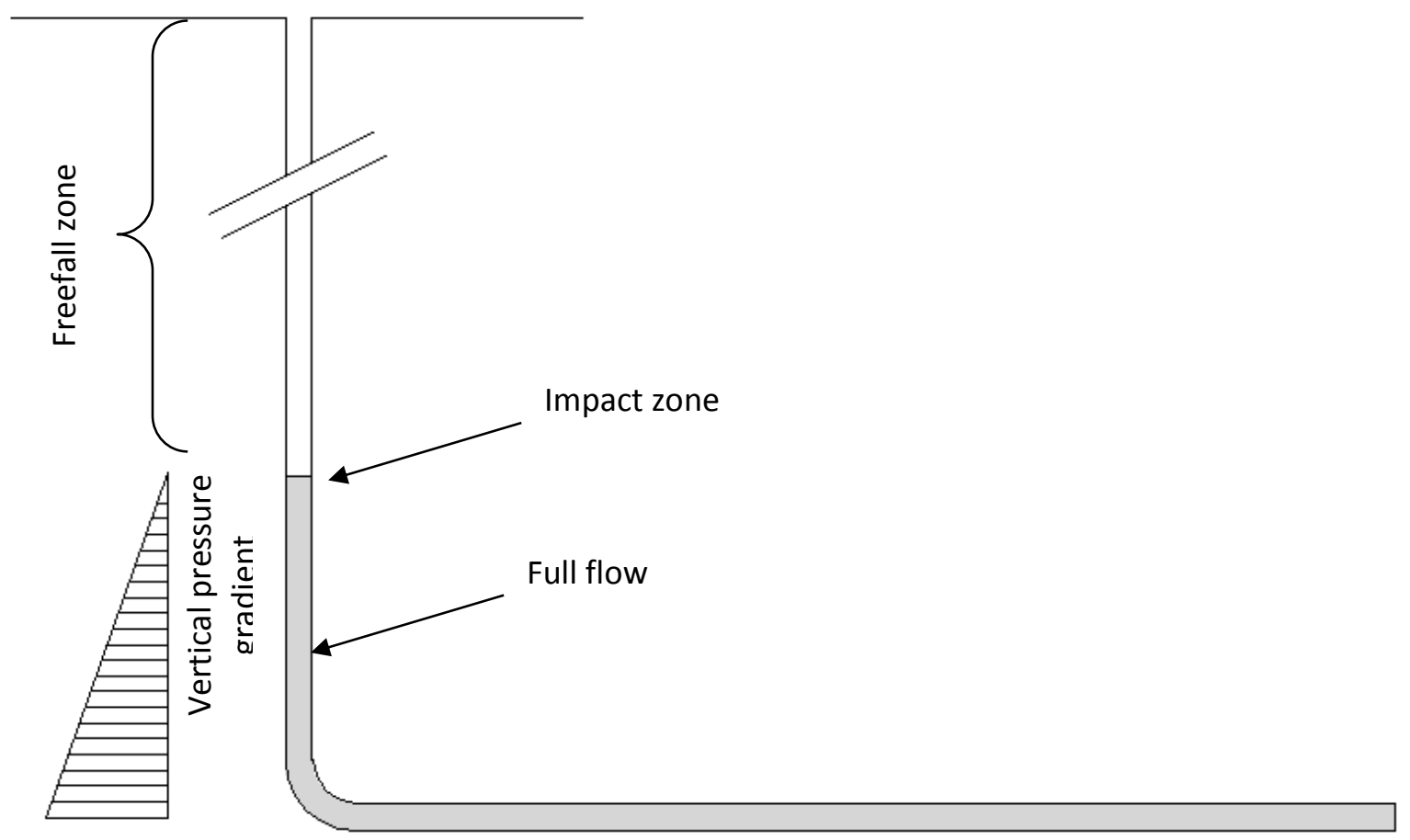

Horizontal pressure gradient

\section{Figure 7 Typical free fall reticulation}

Very high velocities are reached in the free fall zone resulting in excessive wear of boreholes or shaft piping. Furthermore, the impact area where the falling fill meets the near static column of fill is also an area for wear and can lead to excessive bowling of the borehole in this area.

In cased sections of the borehole, excessive flow velocities typically leads to the gouging or barrelling type wear seen in the visual inspections and illustrated in Figure 1. This wear results in breaches to the casing and further wear and failure of the ground behind the casing. Ground water inflow may occur once the casing is breached, further impacting paste quality and flow behaviour as it interacts with the paste.

In uncased sections of borehole, wear will ultimately lead to bowling of the borehole and the development of an uncontrolled void. Flushing of such voids is often ineffective and results in residual paste curing, which can later dislodge and block the system during subsequent pours.

The initial hydraulic assessment confirmed that free fall is taking place in the main borehole, as shown in the hydraulic grade line plot presented as Figure 8. 


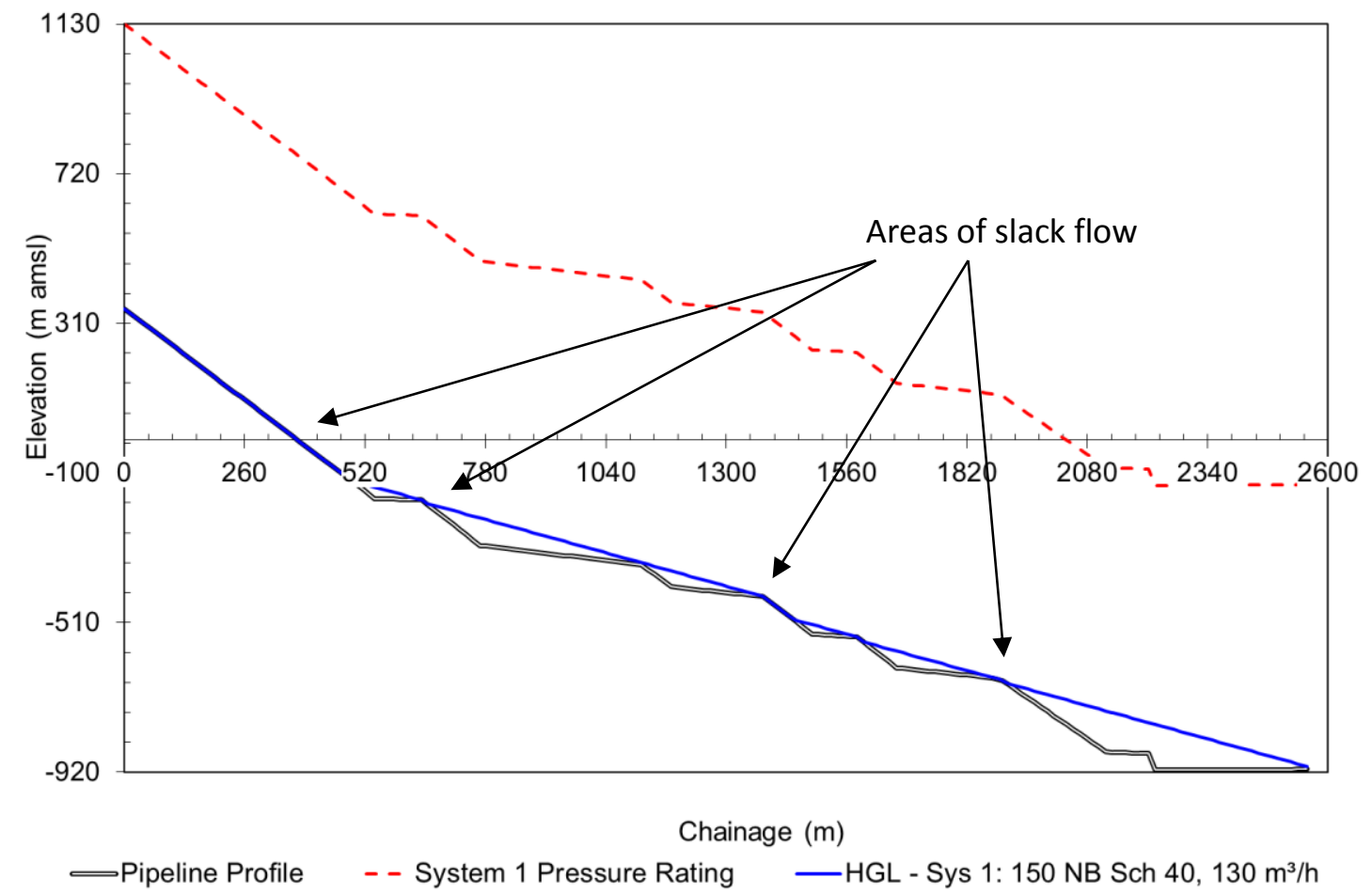

Figure 8 Hydraulic grade line plot - Initial assessment of Gwalia paste reticulation system

The horizontal axis in Figure 8 represents the actual pipeline length and the vertical axis represents the elevation difference in meters. The hydraulic grade line is presented by the solid line and the slope of this grade line equals the friction losses, expressed in meters slurry per metre of pipeline.

If the hydraulic grade line lies on the pipeline profile, this indicates negative pipeline pressures at this point. Slack flow conditions arise when the absolute pressure inside a pipeline falls below the liquid or slurry vapour pressure. For engineering design purposes, slack flow conditions are assumed to exist if the hydraulic grade line intersects the pipeline profile.

During slack flow, the slurry will flow with a free surface in the slack flow section (i.e. open channel or launder flow). If the pipeline slope is steeper than the hydraulic gradient, the slurry will accelerate until it reaches a velocity such that the friction losses equal the pipeline slope. This velocity may be significantly higher than the full flow rate and in slurry or paste fill result in rapid erosion of the pipeline invert.

In Figure 8, it can be seen that in addition to free fall over most of the length of the primary borehole, slack flow conditions also occur at multiple points along the pipeline route resulting in excessive wear in these sections also.

\subsection{Proposed changes to improve the system operation}

Various options can be considered to improve the system operation and to reduce the wear in the borehole, all of which aim ultimately to enable the system to run with a full column of paste fill in the entire borehole.

After consideration of the system constraints, a number of the possible solutions were proposed. These included:

1. Increasing the flow rate of the paste fill to ensure full flow conditions in the borehole pipe.

2. Increasing the concentration of the paste fill to increase the friction losses in the system.

3. Reducing the pipe diameter of the reticulation system when extending the system to the deeper levels. 
The influence of option 2 above is illustrated in an updated hydraulic grade line plot shown below in Figure 9. The updated hydraulic grade line plot for option 1 will be similar to the results presented in Figure 9, but instead of the density, the flow rate will have been increased.

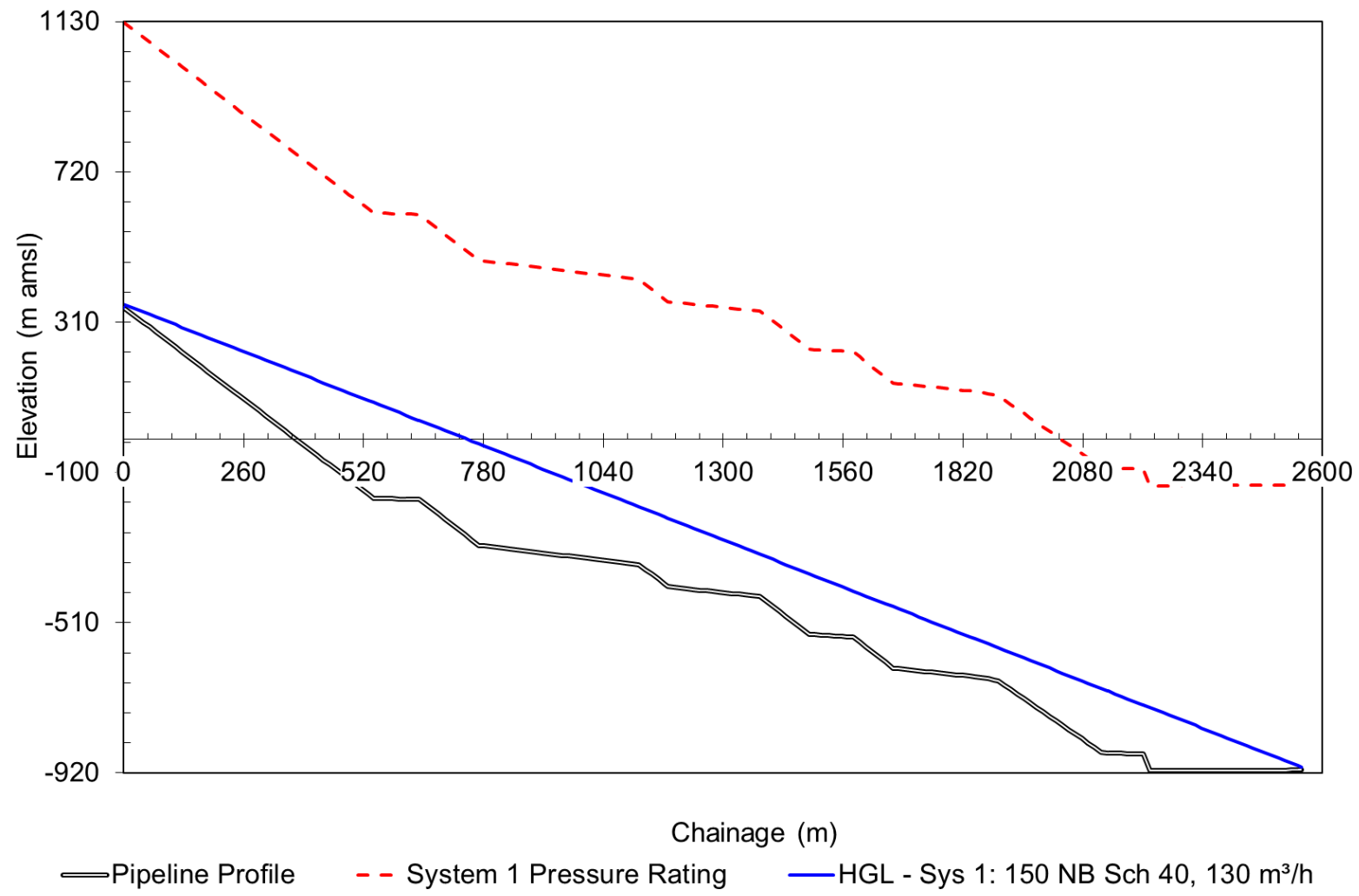

Figure 9 Hydraulic grade line with increased paste density

When comparing the results presented in Figure 9 with Figure 8, it can be seen that the blue line is not lying on top of the pipeline profile nor is it intersecting it, indicating that a positive pressure is present in the system. In addition, it can be seen that the grade line is well below the maximum rated pressure of the backfill pipeline which indicates that it is safe to operate the system in full flow conditions.

The slope of the hydraulic grade line presented in Figure 9 is equal to the elevation difference divided by the actual pipeline length. Changes to the elevation of the discharge point, pipeline length or material properties will change the slope of the hydraulic grade line, requiring a rebalancing of the system (e.g. through piping configuration or material changes) in order to maintain full flow.

The successful operation of a gravity system lies in providing a paste fill system that can react to the system variations to effect the required change in the slope of the hydraulic grade line in order to maintain full flow conditions.

\subsection{Backfill system extension}

It is proposed to install a reduced pipe diameter for any future extensions of the backfill reticulation system, especially when extending into deeper levels in order to increase the friction losses per metre pipeline, i.e. option 3 described above. Figure 10 presents a hydraulic grade line plot of the extended backfill system indicated in Figure 6. 


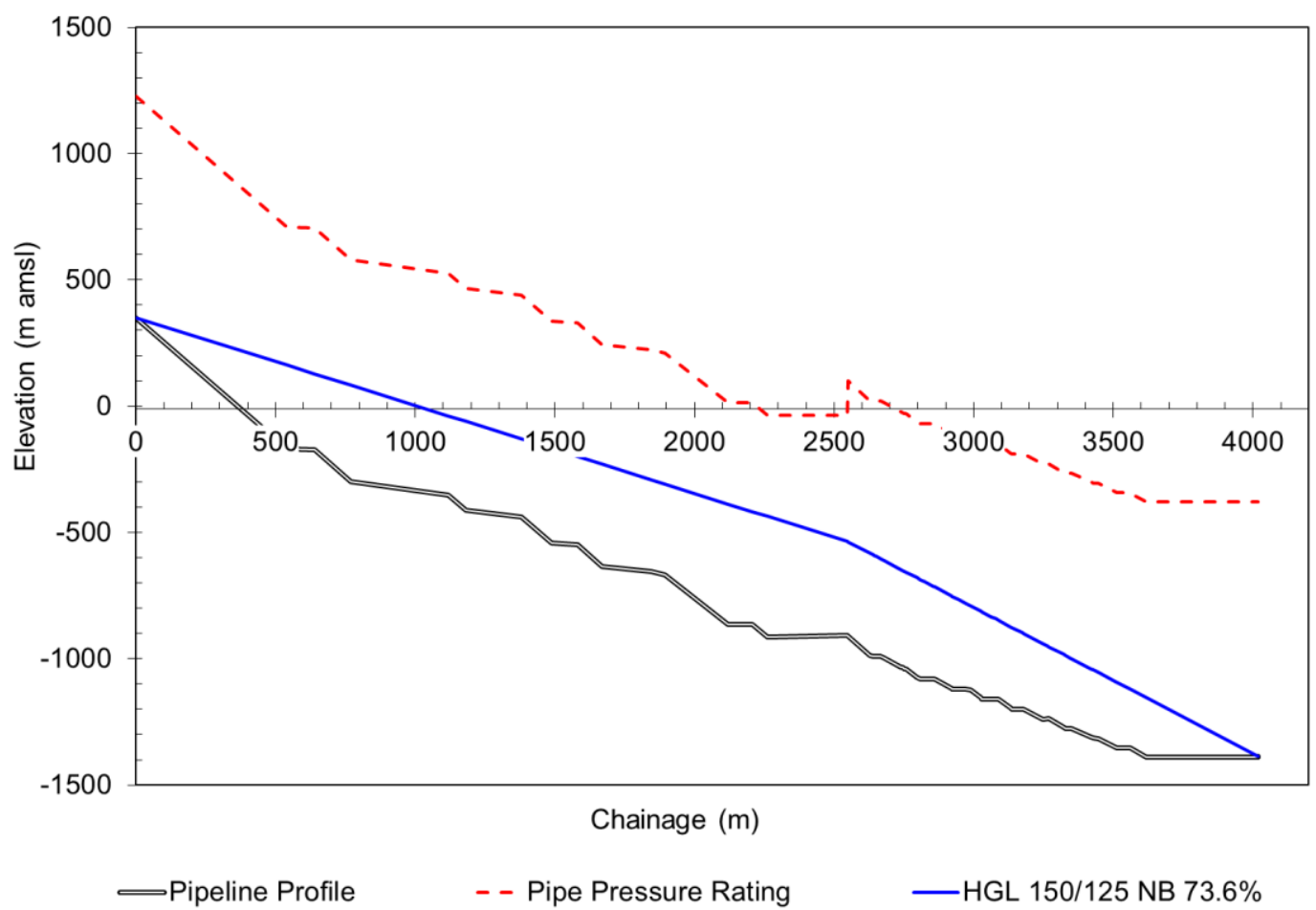

Figure 10 Hydraulic grade line extended system with a smaller diameter pipe

It is proposed to use a $125 \mathrm{~mm}$ NB bore backfill pipe for the deeper levels where the change in slope of the hydraulic grade line presents the transition from the existing $150 \mathrm{~mm}$ NB to the new $125 \mathrm{~mm}$ NB pipe. The reduced pipe diameter will result in a slight increase in operating pressure up stream of the transition point, but the entire grade line is still below the maximum rated pressure of the system and thus safe.

The incorporation of a smaller sized pipe in the lower section of the Gwalia system has both advantages and disadvantages that must be weighed when considering this option.

The advantage of changing of the pipe diameter is that this option involves a permanent, physical change which means that the new pipeline will provide the necessary additional friction to the system to allow for variations in paste quality or tailings conditions. Reducing the pipe size of the bottom portion of the piping system has the greatest impact on the hydraulic grade line of the entire system. Note that doing a similar change only in the middle of the system would not have as significant an effect and could even hinder the overall hydraulics.

It is acknowledged that a $125 \mathrm{~mm}$ NB pipe is not a commonly used pipe and that this can present purchasing challenges. A change in pipe size necessitates the purchasing and warehousing of a second size of coupling and pipe fittings. Pipe supports should be verified for compatibility. The transition point of the two pipe sizes will be a potential blockage point. This risk can be minimised through the installation of a long, gradual reducer to allow the materials to realign gradually in the pipeline. The screen at the hopper should also be aligned to this smaller pipe diameter.

The three options proposed would promote full flow conditions in the paste fill reticulation system.

\section{$4 \quad$ Backfill system management}

\subsection{Paste fill system review and best practices}

As part of the Gwalia life of mine backfill system review, the paste fill system management was examined with respect to the paste fill integration into the mining cycle and the practices in place to continuously 
meet paste fill production, safety and quality objectives. These practices take into account maintenance and also include the operational systems which enable the perpetual success of the paste fill operation.

The Gwalia mine review identifies challenges which many other backfill operations experience and highlighted successful practices from which other sites can benefit. A selection of these has been grouped into a set of best practices as described in the following sections.

\subsubsection{Give paste fill equal importance}

One of the objectives of the Gwalia life of mine backfill system review was to review the planned maintenance schedule of the plant and reticulation system. There is a maintenance system in place overseen by the maintenance department which defines the regular preventive maintenance (PM) of the plant equipment required to ensure system availability both short term and long term. From discussions with the site personnel, one of the major obstacles to maintenance of the paste fill system is not the components of PM program itself, but that priority is given to other processes to the detriment of the paste fill system. This imbalance results in skipped PMs, which accumulate, ending in larger maintenance later on, and creates an emergency based, instead of a preventative based, maintenance strategy. The Gwalia paste plant is physically isolated from the concentrator in terms of plant location and due to the fact that the tailings feeding the paste plant are excavated from nearby tailings facility instead of using a direct tailings feed from the concentrator. This situation promotes the divide between priorities as there is a tendency not to consider the paste plant as part of the larger concentrator maintenance structure.

Lack of equal priority is a common theme of backfill operations, sometimes referred to as the 'poor cousin syndrome'. It is seen in both maintenance and plant operation. Often the backfill process is required to share equipment and operators with other departments. While this scenario may be necessary due to budget cuts or personnel constraints, it can only work successfully if the necessary priorities are given to the backfill tasks to ensure the effective operation and maintenance of the system. Backfill systems are vulnerable to lack of priority because the systems as a whole have little redundancy. Often little attention is given until something goes wrong - which means the system is shutdown. As some operations have experienced, it is often only when the lack of backfill directly affects mining production that the attention turns to system maintenance or labour issues.

\subsubsection{Track the reasons for downtime by area}

Management can develop the equal priority attitude by focusing on the PM execution performance and downtime tracking for the backfill system. Reduction in PM execution delay will improve availability as early troubleshooting will reduce the severity of repairs. Tracking downtime reasons is an essential tool to identify where operational and maintenance improvements can be made. It is informative to note the split between underground maintenance, plant maintenance and operational downtime. The analysis should differentiate between planned and unplanned maintenance, acceptable operational downtime (cure period, reasonable line change times between stopes) and excessive operation downtime. Providing predefined groups of downtime reasons to which downtime can be coded can help with the inputting and analysis of the data. While plant maintenance is often blamed for the process downtime, further investigation often shows downtime due to operational factors, such as scheduling and manning roster choices, can have significant impact on paste plant run time.

A sample of the Gwalia downtime data for 2013 was used to estimate their downtime breakdown. This was only indicative as, while the downtime was tracked consistently, the reasons for the downtime were not always recorded. Improving this last step of the downtime tracking will improve the confidence in the data allowing Gwalia to focus on the key downtime drivers. Operational downtime can include delays such as no operator to start the pour, no place to pour, curing time and excessive time for pipeline switches or barricade construction. Downtime allocated to the Gwalia paste plant was estimated at half the total operational downtime. Plant delays can include unplanned and planned maintenance, lack of material for paste fill, haulage issues, cement feeder problems, instrumentation and electrical issues. Underground 
related delays were estimated at $43 \%$ of the overall downtime and include issues such as barricade problems, plugging, change-outs and leaks in piping or boreholes.

\subsubsection{Designate a backfill coordinator}

Backfill systems are a unique situation in that they fall between two groups: the mill and the mine. They have the maintenance and operational requirements of a plant but they also have the underground infrastructure and constraints of a mine. There is a forced interaction between the two groups but often it is not a coordinated effort.

Gwalia has a frequently used structure for the paste fill system in that there are different people looking after the underground paste fill system operation to those responsible for the surface paste plant operation. There are also separate groups handling maintenance, construction, tailings haulage and backfilling schedule. Gwalia has the added challenge of a fly-in fly-out schedule, which heightens the need for effective coordination between groups. A common complaint from other paste plant operations, echoed by Gwalia, is that while there are many competent people taking care of specific parts of the paste fill process, there is not one individual who knows and is responsible for the whole process.

A backfill coordinator provides the link between the various groups implicated in the backfilling process. The coordinator sees the overall process and schedule and can smooth the interaction between the groups by providing a common understanding of each parties concerns and constraints. This is often a position that is instigated after an incident in the paste fill operation.

\subsubsection{Use instrumentation effectively}

Paste fill systems are highly instrumented compared to their hydraulic fill counterparts, especially on the underground pipeline. The pressure gauges on the paste fill pipeline are the operator's 'eyes' in the underground system. In general, more pressure information is better, especially when an upset occurs. Cameras at the stope enable the plant operator to see the final product. This decreases downtime by allowing paste operation through shift change and blasts. In the plant, instrumentation plays a critical role in paste fill quality control. Simple instruments such as the tailings moisture probe and binder weigh scale are important for proper paste production because they affect the final paste recipe (ratio of water, binder and tailings addition). When these instruments are not functional or have lost their calibration, the paste quality and production are at risk. At the time of the visit, the moisture probe was off-line and an alternative method of calculating the water addition was required. Work-arounds are susceptible to operator error as they are often manual processes requiring compensation through other system controls and can by-pass internal checks.

Calibration is important and is performed regularly at Gwalia. In addition, regular checks by the operator of key variables can help identify problems before they impact the paste production. For example, manual moisture reading taken once per shift can flag probe malfunctions and provide operators with a backup reading for the paste recipe calculation.

Maintenance is the key to effective use of instrumentation. Operators will stop using information from instruments shown to be unreliable in the past. Pressure gauges are often susceptible to this. For example, an operator risks misinterpreting the underground pipeline status if pressure gauges indicating zero are disregarded as 'always broken' instead of being flagged as a system upset. Timely repair of instrumentation and frequent communication with the operators as to the repair status of these instruments can help avoid process upsets due to miscommunication.

\subsubsection{Be proactive with pipeline wear}

Pipeline wear is an issue for many paste fill systems. It is important to establish the pipeline wear rates early in the project life. Gwalia has exhibited this philosophy in its non-destructive testing (NDT) program. The program includes measurement of all spools in the pipeline on a yearly basis and pipes changed out as necessary. Analysis of this data will develop an understanding of the wear profile of the underground 
distribution system which can be used to plan maintenance and budget the pipe replacement schedule based on the LOM plan for each level. Wear rate analysis will highlight areas of high wear which can be indicators of localised problems, such as slack flow in the line, which can then be minimised with adjustments to pipeline configuration.

A wear monitoring program and database enables the operation to predict wear rates and plan pipeline maintenance. Thickness measurement should be conducted quarterly at the start of the project to establish a baseline. The measurement frequency may be reduced in later years, if wear rates merit.

A similar thickness measurement program should be initiated for the paste fill boreholes using camera or other measuring techniques such as caliper or acoustic televiewer surveys. Regular surveys are important to obtain information before casing is ruptured or obstructed, at which point it is not usually possible to send the instruments down the borehole for risk of blockage and loss of the instrument. The borehole camera and casing thickness investigations should be performed yearly or more frequently if the level piping thickness testing indicates a higher wear rate is likely.

\section{Conclusions}

The operational review was initiated by SBM following a blockage incident in the paste fill reticulation system, which significantly impacted on the operation of the entire mine, the implications of which were felt for many months afterwards as the mine schedule was progressively normalised. Such reviews are constructive and, where possible, should be implemented proactively rather than reactively.

This review demonstrated that, for the most part, the paste fill system at Gwalia works well and supports the overall mining operation. The review has, however, identified areas of operational and managerial improvement which if implemented will improve the reliability, consistency and security of the operation.

An important recommendation is a thorough understanding of the feed material, especially when obtaining it from an old tailings facility. Such information enables the operators to either modify the feed (blending) such that optimal paste consistency is maintained or, where this is not possible, at least appreciate and understand the variation so that it can be accommodated in the plant operation.

Consistency of product is a key bench mark for a backfill plant operation, giving confidence in the product and enabling optimisation of the reticulation system operation. Essential to this is the mixer: ensuring ample mixing capacity and control gives the plant the best opportunity of maintaining the desired consistency.

The reticulation system is often the source of backfill system failures and interruptions, as it is often poorly understood by designers and operators. Furthermore, much of it is hidden from sight and so issues are rarely seen until it is too late. Designing a system to operate in full flow and to match the performance envelop of the backfill plant is critical, as is developing and implementing proactive monitoring and maintenance of the system.

Other key management tasks include ensuring that the paste fill operation receives clear ownership and the operational and maintenance support it needs for proactive maintenance and operational strategies to succeed. This can include designating a backfill coordinator, tracking and analysing causes of downtime, pipeline wear monitoring and ensuring instrumentation is reliable.

\section{Acknowledgement}

The authors would like to thank St Barbara Ltd and its staff at Gwalia for granting permission to publish this paper. 
